\title{
O Y-Juca Pirama dos Pampas: o drama de José Bernardino dos Santos
}

\begin{abstract}
Resumo: O drama de José Bernardino dos Santos, Y-Juca Pirama, busca inspiração na obra homônima do poeta Antônio Gonçalves Dias. A aparente construção do drama do autor rio-grandense, no século XIX, toma outra conotação no contexto da nascente literatura sulina: os recursos poéticos que configuram o indianismo brasileiro, transferidos ao Rio Grande, colaboram para a manifestação da tendência mais marcante dessa literatura, qual seja, o regionalismo literário.

Palavras-chave: Poesia romântica, Drama romântico, Rio Grande do Sul.
\end{abstract}

Território situado no extremo sul do Brasil e em constante disputa pelas coroas portuguesa e espanhola, o Rio Grande desenvolveu um modus vivendi peculiar, mais voltado para si do que para o exterior, explorando as características da vida pastoril e guerreira, próprias de suas condições históricas. O Romantismo, que orientou as propostas nacionalistas e a literatura brasileira nascente, chegou à Província quando já estava em decadência em outros espaços culturais, especialmente o Rio de Janeiro. No entanto, se tardio, o Romatismo marcou a 
produção dos autores mais representativos da geração que, ao final da década de 1860, iniciou a organização e a promoção da vida literária rio-grandense. Os versos e os dramas de Gonçalves Dias repercutiram entre os agremiados da novel Sociedade Partenon Literário, fundada em Porto Alegre, em 1868, e inspiraram os poemas dos escritores filiados a essa sociedade literária.

Um ano após a fundação do Partenon, José Bernardino dos Santos escreveu Quadros da vida selvagem - Y-Juca Pirama, poesia de A. Gonçalves Dias, vertida em drama especialmente escrito para ser oferecido à distinta atriz dramática Angelina Marquelou, cuja inspiração buscou diretamente na obra homônima do autor de Os timbiras. O fato, que poderia apenas sinalizar o apreço do jovem romântico ao autor mais representativo do indianismo brasileiro, toma outras conotações e revela que o indianismo romântico teve repercussões mais amplas na literatura do Rio Grande, especialmente na construção do tipo regional - o gaúcho, promovido pela Sociedade Partenon Literário.

\section{1 - A Sociedade Partenon Literário e a literatura rio- grandense}

Ao final da década de 1860, quando os gaúchos estavam envolvidos na guerra do Paraguai, surgiu, em Porto Alegre, um empreendimento de caráter cultural - a Sociedade Partenon Literário. Fundada em 18 de junho, com o propósito de organizar a vida literária no Rio Grande, a entidade atuou, com algumas interrupções, até 1886, quando, por razões de ordem interna e fatores políticos, extinguiu-se finalmente. Nesse período, o Partenon Literário tornou-se o marco fundamental da literatura e da cultura da Província, de tal modo que a história da literatura do Rio Grande inicia sua trajetória por esse agrupamento formado por um conjunto expressivo de intelectuais, que se tornou conhecido como "a geração do Partenon".

1. Estudos recentes têm trazido à luz novos dados sobre a duração da Sociedade Partenon Literário. Entre esses, destaco a tese de Doutorado de Mauro Nicola Póvoas, defendida no PPGL/PUCRS, intitulada "Uma história da literatura: periódicos, memória e sistema literário no Rio Grande do Sul do século XIX". Segundo seu autor, há um documento do Partenon Literário datado em 1886 que possibilita comprovar a existência da agremiação, portanto, quase ao final da década de oitenta do século XIX. 
Desde o momento de sua instalação e nos anos seguintes, seus líderes e agremiados concretizaram as aspirações e os objetivos definidos em 1868, evitando que o Partenon tomasse o rumo de outras entidades similares que, em pouco tempo, colocaram ponto final em sua trajetória. Para isso, foi traçado um programa de ação, apresentado por Apolinário Porto Alegre no discurso de instalação da Sociedade e publicado no primeiro número da Revista da Sociedade, lançado já no ano seguinte ao de sua inauguração. Nele, estão expressos os compromissos basilares da entidade:

O Partenon criou uma tribuna, para pugna oratória; uma biblioteca, onde reunirá as obras mais importantes relativas à grandiosa trindade de seus estudos: filosofia, história e literatura; aulas noturnas para os sócios que quiserem dedicar-se sem dificuldades ao granjeio da ciência $(\ldots)^{2}$

As questões de ordem literária, política e cultural que envolviam os agremiados da novel entidade passaram a ser amplamente discutidas e difundidas, sobretudo nos saraus literários. Promovidos pelos associados, nesses eventos realizavam-se debates sobre temas candentes da época, apresentados pelos sócios da entidade, por suas esposas ou por pessoas convidadas às sessões. Verdadeiras oportunidades para a defesa de teses, os saraus agregavam a parte social à cultural e possibilitavam a presença de mulheres, numa época em que a participação feminina era ainda restrita. Luciana de Abreu, a mulher mais representativa desse grupo, marcou seus pronunciamentos em defesa da participação das mulheres e do espaço a elas destinado no lar de família.

A biblioteca que os partenonistas formaram reuniu obras importantes nas áreas de Filosofia, História e Literatura, chegando a contar com mais de 6.000 volumes; a ela, agregaram um museu de ciências naturais, que incluía peças de Mineralogia, Arqueologia, Numismática e Zoologia.

As aulas noturnas foram uma de suas inciativas mais duradouras e somente por volta de 1884, por falta de recursos e inexistência de local próprio,

2. Este fragmento consta do "Programa da Sociedade Partenon Literário" e está publicado no volume n. 1 da Revista Mensal da Sociedade Partenon Literário, lançado em março de 1869. Posteriormente, foi transcrito em: ZILBERMAN, Regina; SILVEIRA, Carmen Consuelo; BAUMGARTEN, Carlos Alexandre. O Partenon Literário: poesia e prosa. Antologia. Porto Alegre: EST, 1980. p. 47. 
tiveram de ser suspensas. A correspondência enviada por professores dessas aulas às autoridades responsáveis comprova as condições de funcionamento da atividade. Em carta datada de $1^{\circ}$ de fevereiro de 1884 , um dos docentes registra "o avultado número de alunos, que atualmente frequenta esta aula", 3 chamando a atenção para o pouco espaço de que dispõem para o desenvolvimento do trabalho e para o problema que acarretará à população o fechamento dessas salas. O encerramento das aulas certamente irá "prejudicar os interesses de não pequeno número de cidadãos a quem o Partenon comprometeu-se dar-lhes instrução, e que por seu amor ao estudo, moralidade e disciplina tem feito jus a isso". ${ }^{4}$ Os problemas, porém, não se resumiram às questões físicas ou financeiras, mas atingiram outra área, qual seja, a de discordância com a orientação fornecida pelos responsáveis pela educação, na Província, resultando o fechamento dos cursos noturnos.

Do ponto de vista político, o Partenon envolveu-se na campanha em prol da libertação dos escravos, com a realização de espetáculos no Teatro São Pedro, em Porto Alegre, quando negros cativos eram alforriados muitos anos antes da assinatura da Lei Áurea. Outro tema abraçado pelos agremiados dizia respeito à República, defendida pela maioria dos partenonistas. A tríade, portanto, sobre a qual se pautava o Partenon Literário podia ser expressa, preferencialmente, pela forma Abolição + República, na questão política, e Romantismo, no plano literário.

Mas certamente a iniciativa que alcançou maior repercussão entre todas as demais foi a criação de uma revista, materializando, assim, aquele "núcleo, onde a luz civilizadora se concentrasse nos certames científicos, nos pleitos da tribuna e na discussão transcendente sobre o verdadeiro, o bom e o belo", 5 como

3. ARAÚjO, Ramiro. Documentos sobre a Sociedade Partenon Literário acervo geral, pacote 27/9. V. DULliUS, Fabio. Apolinário Porto Alegre e sua contribuição lítero-social nas revistas do Partenon Literário de 1872 a 1874, jun. 2000. Essas informações encontram-se na Revista do Instituto Histórico e Geográfico do Rio Grande do Sul, Porto Alegre, v. 1, n. 1, jan.mar. 1921, p. 150.

4. ARAújO, Ramiro. Documentos sobre a Sociedade Partenon Literário acervo geral, pacote 27/9. V. DULlius, Fabio. Apolinário Porto Alegre e sua contribuição lítero-social nas revistas do Partenon Literário de 1872 a 1874, jun. 2000. Essas informações encontram-se na Revista do Instituto Histórico e Geográfico do Rio Grande do Sul, Porto Alegre, v. 1, n. 1, jan.mar. 1921, p. 150.

5. Programa. Revista Mensal do Partenon Literário, Porto Alegre, n. 1, mar. 1869. 
consta no Programa da Sociedade. A criação da Revista, considerada tão necessária como as outras iniciativas - a tribuna, a biblioteca, o museu, as aulas noturnas - é justificada nesse mesmo texto, quando o articulista indaga:

Por que criou a última?

$\mathrm{Na}$ antigüidade, o vôo e exibição de idéias não tinha, como nos tempos modernos, limites enquanto ao local. ${ }^{6}$

Por essa razão, o Partenon instituiu a revista mensal como um veículo poderoso, "que irá ao longe levar os frutos de seus talentos e labutações." Sob a divisa - vitam impendere vero - lançavam os partenonistas o seu empreendimento mais audaz e profícuo, o veículo que, extrapolando os muros da agremiação e da Capital da Província, transformou-se no polo irradiador da literatura do Rio Grande.

A Revista colaborou sobremodo para a definição do tipo regional - o gaúcho -, mas consolidou uma ideologia - a democracia campesina - garantidora das instituições rio-grandenses. O retorno a essa proposta era imediato: o candidato ou aspirante a escritor reconhecia nesses valores a matéria para exploração literária e, ao adotá-la, reforçava o conteúdo telúrico, concedendo à incipiente literatura a feição particular de que necessitava para sua aceitação.

Nascida num momento histórico e literário particular, uma vez que a década de setenta do século XIX correspondeu também à de consolidação política do Rio Grande, a Sociedade Partenon Literário aglutinou os valores de ordem política - a independência e o liberalismo, remontando ao tempo da epopeia farrapa - e os transformou em matéria para criação literária, deixando-se conduzir pelas sugestões emanadas do Romantismo. Dessa forma, a exploração do regional, a promoção dos heróis nacionais e a exaltação dos valores próprios da cultura local, preconizadas pelos românticos, associaram-se aos anseios políticos dos riograndenses, e a combinação entre política e literatura foi responsável pela permanência e manutenção dos valores regionais. Enquanto esteve no poder a oligarquia de orientação republicana que dominou a política gaúcha, os temas explorados pela literatura coincidiram com os valores preconizados pelas lideranças

6. Programa. Revista Mensal do Partenon Literário, Porto Alegre, n. 1, mar. 1869.

7. Programa. Revista Mensal do Partenon Literário, Porto Alegre, n. 1, mar. 1869. 
políticas, pois que colaboravam para assegurar a manutenção, no poder, da classe dirigente gaúcha. Nesse caso, o Partenon Literário assumiu uma função especial, porquanto seus filiados foram homens engajados com os ideais da elite política do Rio Grande e, ao mesmo tempo, foi ainda esse grupo que produziu e divulgou o material literário capaz de representar e conformar os anseios da comunidade onde estava inserido.

\section{2 - O drama indianista de José Bernardino dos Santos}

No verão de 1869, apesar de a guerra do Paraguai continuar abalando o império brasileiro e colaborar para tornar mais quente o verão, a programação da capital da Província sulina parecia sofrer mais com a quentura dos dias de janeiro e fevereiro do que propriamente com o calor da guerra. Nos meses dessa longínqua estação, o Grande Cosmorama Mecânico e Fantástico, instalado na rua da Praia, a principal via da cidade, exibiu para adultos e crianças, mediante preços muito módicos, belíssimas vistas de cidades e de exposições internacionais europeias, além de uma coleção completa de dispositivos "de todas as guerras do mundo, de Moisés a Napoleão e destes até os dias presentes", como registra Athos Damasceno Ferreira, em Palco salão e picadeiro em Porto Alegre no século XIX.

Em fins de maio, ocupou a cena do Teatro São Pedro, inaugurado em 1858, com excelentes recursos técnicos, a Companhia Dramática, empresada por José de Almeida Cabral Filho, conhecido dos palcos porto-alegrenses, pois já passara por essa casa de espetáculos em outras ocasiões. O conjunto de Almeida Cabral apresentou-se no teatro da Praça da Matriz e logo arrebatou o público assistente. O repertório escolhido e o seleto corpo de figurantes eram os responsáveis pelo sucesso da temporada. Cabral conhecia o gosto da sociedade e alternava, entre dramas e comédias, como Os íntimos, de Vitorien Sardou, O Capitão Tic, de Labiche e Martin, O castigo de Deus, de Paul Foucher, O velho Cabo de Esquadra, de Dumanoir e Dennery, peças mais leves, que atendiam ao gosto popular: $A$ corda sensivel, Vai torto o mundo, Nem um nem outro, A viúva das camélias, Distraçôes de um marido, Dois gênios iguais não fazem liga. O público deliciavase também com a orquestra do conhecido Maestro Mendanha, responsável pela

8. Ferreira, Athos Damasceno. Palco salão e picadeiro em Porto Alegre no século XIX. Porto Alegre: Globo, 1956. p. 110. (Província, 2). 
abertura das serestas, e com as miscelâneas musicais, em que vozes femininas cantavam canções leves e variadas.

O prestígio da companhia junto à imprensa, a encenação de peças de autores brasileiros e portugueses, como também franceses, que faziam a moda da época, justificavam a lotação esgotada do Teatro São Pedro, quase todas as noites. A reação da crítica era favorável e com o público respondendo positivamente aos espetáculos, as homenagens a atores e atrizes tornaram-se costumeiras. Entre as atrizes, uma, em especial mereceu reconhecimento público. A francesa Antonina Marquelou, primeira atriz dramática da Companhia, foi alvo de várias manifestações de apreço. Uma noite, depois de sua interpretação, foi homenageada com versos por um dos assistentes que, erguendo-se da plateia, em um dos intervalos do espetáculo, recitou-lhe um longo poema, que assim começava: "Flor predileta dos jardins do Eterno, / o céu e a terra a trescalar de odores..." Flores, ramalhetes, versos, volantes, tudo isso era distribuído ao elenco como manifestação de apoio aos atores.

Durante três meses, a Companhia Dramática vivenciou dias de muitos louros e ininterruptos aplausos. No entanto, a tranquilidade foi perturbada por um episódio que envolveu Almeida Cabral, o famoso empresário, e a recém-fundada Sociedade Partenon Literário: quando os partenonistas, fiéis à missão lançada por ocasião da fundação da sociedade, quiseram dar início ao programa abolicionista, realizando uma cerimônia de alforria de escravos, no mesmo teatro usado pelos atores de Cabral, e marcada para o dia da Independência, 7 de setembro, o grupo entrou em entendimento com o empresário, que cedeu o espaço para a atividade. Dias depois, porém, Cabral arrependeu-se do gesto e, por não querer perder dinheiro para a turma de românticos, deu continuidade às apresentações, subestimando a iniciativa do Partenon Literário.

Caldre e Fião, idealizador da sociedade e um dos mais ferrenhos defensores da abolição, atacou Pinheiro Cabral, dando início a uma séria discussão para a qual vieram se juntar outros nomes importantes: Apolinário Porto Alegre (idealizador do Partenon Literário junto com Caldre e Fião), Hilário Ribeiro, José Bernardino dos Santos e alguns outros componentes da entidade, deixando Cabral completamente perturbado em suas ações. Para resolver a polêmica, Cabral veio a público, reavaliou sua atitude, pedindo escusas aos partenonistas, e liberou o teatro para as iniciativas programadas pelos jovens. Logo depois, reconciliado com o Partenon, a companhia de Cabral continuou a ocupar o Teatro São Pedro e a obter relativo sucesso. 
Foi nesse contexto que José Bernardino escreveu a peça Quadros da vida selvagem - Y-Juca Pirama, poesia de A. Gonçalves Dias, vertida em drama especialmente escrito para ser oferecido à distinta atriz dramática Angelina Marquelou e publicado pela Tipografa d'O Rio-Grandense, de Porto Alegre, no mesmo ano de 1869. A empolgação do moço pela bela primeira dama da Companhia o motivava para isso, mas a dedicatória à atriz poderia contribuir para amenizar a querela que se instalara entre os dois grupos. Partia, então do representante do Partenon, a iniciativa de acautelar os ânimos, exacerbados pela voz de Caldre e Fião, o líder da entidade. No entanto, essa hipótese se desfaz, quando se lê o texto introdutório ao drama, no qual o autor apresenta a dedicatória. Nele explicitam-se duas intenções: 1 - a da homenagem, confirmada pelas palavras de Bernardino quando diz que "ungia-se também um desejo meu [dele]: e era de ser eu o primeiro que te oferecesse alguma coisa melhor que palmas, de mais valor que buquêse coroas de flores."; 2 - a da eleição do texto inspirador, quando escreve que os seus "maus versos vão de envolta ao sublime poemeto do imortal cantor das Americanas-intitulado Y-Juca-Pirama". . O elogio expande-se ainda na frase seguinte, quando se empolga e escreve: "A. Gonçalves Dias é um nome e sabe-o o orbe inteiro, que não desaparece como as guirlandas com que laureiam; não! Avulta de mais em mais a cada dia que passa! É pois com um de seus melhores cantos que teci a coroa que hoje te ofereço."

Na versão gaúcha, o canto revela desde o início a sua flagrante adesão ao poema do poeta maior. São quatro personagens em cena: um Tupi, pai de YJuca Pirama; o guerreiro Y-Juca Pirama; o cacique e o pajé da tribo Timbira, a que se associam dois coros - um de mulheres e outro de índios, e a ação que move o drama é idêntica ao de Y-Juca-Pirama de Gonçalves Dias: Y-Juca é preso, prepara-

9. SANTOS, José Bernardino dos. Quadros da vida selvagem. Y-Juca-Pirama. Poesia de A. Gonçalves Dias vertida em drama especialmente escrito para ser oferecido à distinta atriz dram tica Antonina Marquelou. Porto Alegre: Tipografia do Rio-Grandense, 1869. p. X. [Itálicos do texto original].

10santos, José Bernardino dos. Quadros da vida selvagem. Y-Juca-Pirama. Poesia de A. Gonçalves Dias vertida em drama especialmente escrito para ser oferecido à distinta atriz dram tica Antonina Marquelou. Porto Alegre: Tipografia do Rio-Grandense, 1869. p. X. [Itálicos do texto original].

11. SANTOS, José Bernardino dos. Quadros da vida selvagem. Y-JucaPirama. Poesia de A. Gonçalves Dias vertida em drama especialmente escrito para ser oferecido à distinta atriz dram tica Antonina Marquelou. Porto Alegre: Tipografia do Rio-Grandense, 1869. p. X. 
se sua morte pela tribo inimiga, o velho pai de Y-Juca reconhece sua cobardia, pede a morte do filho, mas, no momento final, Y-Juca prova sua coragem, por ações de valentia, e é libertado pela tribo inimiga e redimido pelo pai. Há uma única cena em que os dois textos diferem: falta ao drama de Bernardino a recordação de "um velho Timbira, coberto de glória / [que] Guardou a memória / Do moço guerreiro, do velho Tupi!", como escreveu Gonçalves Dias.

A ação transcorre nos sertões de Maranhão, no começo do século XVII, durante o período holandês. Bernardino transfere, pois, à terra natal de Gonçalves Dias e aos tempos do Brasil colonial os dois quadros dramáticos. No primeiro, composto por cinco cenas, entremeia sua construção literária com a do autor de Primeiros cantos, num jogo intertextual evidente, pois que o texto gonçalvino aparece marcado por aspas para diferençar daquele de criação de Bernardino. Esse quadro inicia quando o coro situa espacialmente o drama e caracteriza a tribo rude dos timbiras. Entra o prisioneiro e o pajé e o cacique buscam identificar o desconhecido. No diálogo que se segue entre Y-Juca Pirama e o cacique, o índio pede clemência ao cacique que diz ser Y-Juca Pirama um covarde. Inicia-se o ritual de morte: a fogueira é acesa, o cabelo do preso é cortado, as mulheres da tribo pintam o seu corpo e colocam os enfeites para a cerimônia final. Ao chegar a hora do sacrifício, o cacique indaga novamente a origem do homem e esse se expressa através do "Canto do guerreiro", de Gonçalves Dias, transcrito no texto do gaúcho. Quando o índio relata a sua história e as condições de seu velho pai, para espanto de todos o cacique manda libertá-lo. Y-Juca Pirama, porém, não quer partir e, no torpor em que se encontra, tem a visão da figura paterna, que o acusa de covarde, ao constatar que seu filho perdera a dignidade de índio valente. No segundo quadro, o velho tupi, pai de Y-Juca Pirama, chega à tribo dos timbiras e exige que o cacique execute o sacrifício, dando a morte a seu próprio filho, por esse ter sido covarde. Y-Juca Pirama reage e investe contra a tribo inimiga e começa uma luta, na qual revela sua força e coragem. O cacique retoma a situação e reconhecendo a coragem do índio preso concilia os homens e, num gesto final, Y-Juca, seu velho pai e o cacique dão-se as mãos, celebrando a paz entre as tribos. O coro fecha o drama, cantando os versos de Gonçalves Dias:

Folga morrendo; porque além dos Andes

Revive o forte,

Que soube ufano contrastar os medos

Da fria morte. 
Rasteira grama exposta ao sol, à chuva,

Lá murcha e pende:

Somente ao tronco, que devassa os ares,

O raio ofende.

Que foi? Tupã mandou que ele caísse,

Como viveu:

E o caçador que o avistou prostrado

Esmoreceu!

Por que, então, José Bernardino dos Santos, mais tarde autor de $A$ douda, romance regional rio-grandense, tomou a obra de Gonçalves Dias como referência e inspiração para tal homenagem? Por que o poeta indianista foi o escolhido dentre os demais escritores brasileiros para orientar o drama do partenonista?

A geração que fundou o Partenon Literário - e entre eles, como se disse, estava José Bernardino dos Santos - bebia nas águas tardias do Romantismo. Vivendo em lutas, décadas por décadas, o Rio Grande se desenvolvera mais nas armas do que nas letras. Agora, a geração de jovens que assume a tarefa de criar uma literatura para sua Província, busca, nos modelos bem-sucedidos, o exemplo a ser seguido. Gonçalves Dias parece oferecer essas condições, pois, como diz Bernardino, o poeta dos sabiás é um nome e o mundo inteiro sabe disso. Talvez aqui importe menos a recepção do autor de Os timbiras (que não chega ao orbe inteiro), mas muito mais o que ele significa enquanto representante da literatura nacional: Gonçalves Dias é um poeta que ocupa um lugar e que concede sentido à sociedade na qual está inserido. Com sua poesia, ele conforma um sentimento e dá vazão ao anseio coletivo de representação da nação brasileira.

É certo que quando Bernardino vai buscar sua inspiração em Gonçalves Dias, o indianismo que ele representa já havia perdido sua força, mas também é sabido que, no Rio Grande, especialmente o Y-Juca-Pirama batia seu compasso entre os agremiados do Partenon. No mesmo ano de 1869, Bernardo Taveira Jr., outro integrante do Partenon Literário, publicara na Arcádia, da cidade de Rio Grande, um poema intitulado "O Membira”, cuja estrofe inicial é a seguinte:

Teu pai já não vive

Querido Membira!

Da tribo Timbira 
Foi bravo e temido:

Seu nome estimado,

Por feitos altivos,

Nos campos festivos

É sempre lembrado. ${ }^{12}$

Construído em oitavas, em versos de redondilha menor, Bernardo Taveira retoma explicitamente o tema, o ritmo e a ambientação do texto gonçalvino. Ao final, encerra o poema com as seguintes palavras:

\author{
Adeus, ó meu filho!... \\ Recorda a memória, \\ Que brilha com glória \\ Nas armas que dou-te - \\ De um nobre Timbira! \\ Teu pai foi um braço, \\ Jamais foi escravo... \\ Adeus, ó Membira! ${ }^{13}$
}

Os versos de Gonçalves Dias encontram eco no distante território sulino e sugerem que os feitos e a liberdade, preconizados pelo poema romântico, podem servir de modelo e inspiração para a geração sulina. Afinal, os ideais de liberdade e o rechaço à escravidão constituíam ideais do grupo do Partenon. Transferir esses sentimentos à poesia do Rio Grande foi tarefa em que logo se empenharam os membros da sociedade. Em 1869, Apolinário Porto Alegre, o mentor do grupo, assume essa proposta e escreve "Canto do campeiro", nele apresentando o campeiro, tipo regional do Sul do Brasil. O compasso é idêntico, mas o conteúdo dos versos já revela que o índio foi substituído pelo elemento

12. TAVEIRA, Jr. Bernardo. O Membira. Arcádia, Jornal Ilustrado, Histórico e Biográfico, Rio Grande, 14 maio 1869. [Reproduzido em ZILBERMAN, Regina; SILVEIRA, Carmen Consuelo; BAUMGARTEN, Carlos Alexandre. O Partenon Literário: poesia e prosa. Antologia. Porto Alegre: EST, 1980. p. 140$]$.

13. TAVEIRA, Jr. Bernardo. O Membira. Arcádia, Jornal Ilustrado, Histórico e Biográfico, Rio Grande, 14 maio 1869. [Reproduzido em ZILBERMAN, Regina; SILVEIRA, Carmen Consuelo; BAUMGARTEN, Carlos Alexandre. O Partenon Literário: poesia e prosa. Antologia. Porto Alegre: EST, 1980. p. 140$]$. 
local e que os ideais preconizados ajustam-se às pretensões dos homens gaúchos. A Revolução Farroupilha, que acabara em 1845, deixou vivos seus pressupostos de liberdade, autonomia e grandeza. Apolinário Porto Alegre expressou em seus versos a exaltação do homem sulino, a glorificação da luta, os ideais de liberdade e fortalecimento do Rio Grande:

Avante, ginete

Dos campos do sul!

Quem pode contigo,

Que, afeito ao perigo,

A sanha do imigo

Não temes, taful?

Avante! Galopa

Num bom galopar:

Os laços e bolas,

Ferinas pistolas

Já fiz preparar;

Avante, ginete

Num bom galopar!

Os versos exaltam a epopeia farrapa, considerada como o decênio que há de ficar na memória dos rio-grandenses, colaborando para construir o mito sobre essa luta. Para os rio-grandenses, a Revolução Farroupilha torna-se, assim (e permanece até os dias atuais), como a manifestação da rebeldia contra o governo imperial e assume a conotação de episódio fundador da história do Rio Grande. Diz o poeta:

Soberbo decênio

A história gravou;

Decênio de glória

De eterna memória,

Que à luz da vitória

A pátria vingou!

Avante! Galopa

Num bom galopar:

Os laços e bolas,

Ferinas pistolas

Já fiz preparar; 
Avante, ginete

Num bom galopar!

São, porém, os versos finais os mais significativos no que se refere à exaltação do Rio Grande e do campeiro que nele habita:

Não dorme o Rio Grande...

Erguido de pé:

Quem pode vencê-lo?

Se sabem temê-lo

Capaz de retê-lo

No jugo, quem é?

Avante! Galopa

Num bom galopar:

Os laços e bolas,

Ferinas pistolas

Já fiz preparar;

Avante, ginete

Num bom galopar!

As lanças s'enristam

Nos campos de cá,

Do livre campeiro,

Que em lutas fagueiro,

Como ele não há.

Avante! Galopa

Num bom galopar:

Os laços e bolas,

Ferinas pistolas

Já fiz preparar;

Avante, ginete

Num bom galopar! ${ }^{14}$

14. PORTO ALEGRE, Apolinário. Canto do campeiro. Arcádia, Jornal Ilustrado, Histórico e Biográfico, Rio Grande, 1870. [Reproduzido em ZILBERMan, Regina; SILVEIRA, Carmen Consuelo; BAUMGarTEN, Carlos Alexandre. O Partenon Literário: poesia e prosa. Antologia. Porto Alegre: EST, 1980. p. 74-76]. 
Se o Romantismo brasileiro e especialmente seu filão indianista concretizou o desejo de sua geração de se ver reproduzida na literatura, a geração do Partenon Literário seguiu essa tendência a seu modo. No Rio Grande, o índio de Gonçalves Dias foi cantado e serviu de modelo para o exercício poético, mas logo ficou compreensível que ele deveria ser substituído por outro tipo - o gaúcho. A lição é a mesma, a da representação das particularidades locais, mas a expressão local, para os rio-grandenses, traduz-se no aproveitamento do tipo genuinamente regional. Aliás, essa era a meta dos partenonistas: criar a expressão literária de sua terra, seguindo a orientação dos românticos nacionalistas.

Há, pois, um marco literário entre os agremiados do Partenon que provém do Romantismo, mas há um acento particular que orienta o fazer literário e que ensina o que os gaúchos entendem por cor local: o índio, nesse caso, transforma-se no gaúcho; as terras planas e extensas da Campanha substituem as florestas; os valores da liberdade e da independência (por isso a luta contra a abolição), contidas no bojo do Romantismo, encontram espaço no território riograndense. O Rio Grande torna-se o locus para o exercício desses valores e, por isso, é compreensível por que, no Rio Grande, a Campanha substitui a floresta, o gaúcho ocupa o lugar do indígena e a luta farrapa consolida-se como momento fundador da Província sulina. Transferem-se, assim, os elementos do indianismo para o solo gaúcho e essa adaptação possibilita a conformação do regionalismo literário.

Se o drama de José Bernardino dos Santos - Quadros da vida selvagem - Y-Juca-Pirama, poesia de A. Gonçalves Dias, vertida em drama, constitui aparentemente um mero exercício poético de um jovem de vinte anos, por certo, outro sentido ele expressa: a orientação para a literatura rio-grandense surge sob a égide da escola romântica e, entre seus representantes, os versos indianistas de Gonçalves Dias motivam a construção de uma literatura singular, no Sul do Brasil. Nesse caso, o indianismo, aparentemente pouco afeito ao território sulino, toma um significado mais amplo e ensina que seu compasso e seu tema podem ser transferidos para o Rio Grande para impulsionar sua nascente literatura e seu filão mais representativo: o regionalismo literário. 
José Bernardino dos Santos's play: Y-Juca-Pirama of the Pampas

Abstract: The play Y-Juca Pirama, by José Bernardino dos Santos, is inspired by a homonymous poem by Gonçalves Dias. Santos' Romantic play, based on a poem by a Northern writer, in the nineteenth century, takes on a different connotation in the context of the rising Southern literature: the poetic devices that shape Brazilian Indianism, when transferred to Rio Grande do Sul, strengthen the most remarkable trend in Brazilian Southern literature, namely Regionalism.

Keywords: Romantic poetry, Romantic drama, Rio Grande do Sul.

$$
\text { Referências }
$$

DULliUS, Fabio. Apolinário Porto Alegre e sua contribuição lítero-social nas revistas do Partenon Literário de 1872 a 1874. 2000. Monografia (História). Pontifícia Universidade Católica do Rio Grande do Sul, Porto Alegre, 2000.

FERREIRA, Athos Damasceno. Palco salão e picadeiro em Porto Alegre no século XIX. Porto Alegre: Globo, 1956. p. 110. (Província, 2).

MOREIRA, Maria Eunice. Nacionalismo literário e crítica romântica. Porto Alegre: IEL, 1991.

PORTO ALEGRE, Álvaro. O Partenon Literário. Ensaio lítero-histórico. Porto Alegre: Thurmann, 1962.

PORTO ALEGRE, Apolinário; CASTRO, João F. de; GUIMARÃES, Gaspar. Documento sobre a Sociedade Partenon Literário. Revista do Instituto Histórico e Geográfico do Rio Grande do Sul. Porto Alegre, v. 1. n. 1, jan./mar. 1921.

PÓVOAS, Mauro Nicola. Uma história da literatura: periódicos, memória e sistema literário no Rio Grande do Sul do século XIX. Tese (Doutorado em Letras). Programa de Pós-Graduação em Letras, Pontifícia Universidade Católica do Rio Grande do Sul, Porto Alegre, 2005.

PROGRAmA. Revista Mensal do Partenon Literário, Porto Alegre, n. 1, mar. 1869.

TILL, E. Rodrigues. Contribuição à história do Partenon Literário. In: HESSEL, Lothar et alii. O Partenon Literário e sua obra. Porto Alegre: Flama; IEL, 1976.

ZILBERMAN, Regina; SILVEIRA, Carmen Consuelo; BAUMGARTEN, Carlos Alexandre. O Partenon Literário: poesia e prosa. Antologia. Porto Alegre: EST, 1980.

Revista do Instituto Histórico e Geográfico do Rio Grande do Sul. Porto Alegre, v. 1, n. 1, jan.-mar. 1921.

SANTOS, José Bernardino dos. Quadros da vida selvagem. Y-Juca-Pirama. Poesia de A. Gonçalves Dias vertida em drama especialmente escrito para ser oferecido à distinta atriz dramática Antonina Marquelou. Porto Alegre: Tipografia do Rio-Grandense, 1869. p. X.

SILVA, João Pinto da. História literária do Rio Grande do Sul. Porto Alegre: Globo, 1924. p. 57. 